\title{
A Gestão da Matéria e a Gestão de Classe no ensino de Matemática: uma perspectiva sobre a metodologia "Lógica do Cálculo"
}

Carla Camargo Fonseca 1

Universidade La Salle, Programa de Pós-Graduação em Educação, Canoas, RS, Brasil

Gabriele Bonotto Silva ${ }^{2}$

Universidade La Salle, Programa de Pós-Graduação em Educação, Canoas, RS, Brasil

Vera Lucia Felicetti ${ }^{3}$

Universidade La Salle, Programa de Pós-Graduação em Educação, Canoas, RS, Brasil

\section{Resumo}

Este artigo tem como objetivo investigar aspectos do desenvolvimento do ensino da Matemática em um $1^{\circ}$ ano do Ensino Fundamental a partir da aplicação da metodologia "Lógica do Cálculo" (SIMONS, 2013). O estudo tem cunho qualitativo, optando-se pela técnica de estudo de caso. A coleta de dados aconteceu em uma escola particular da cidade de Canoas (RS), por meio da observação in loco e também mediante entrevista semiestruturada com a professora da turma observada. A análise dos dados foi realizada tendo como base a técnica da análise textual discursiva. A análise do corpus, constituído pelas observações e pela entrevista com a professora, gerou duas categorias: Gestão da Matéria e Gestão da Classe. A partir dessa categorização obteve-se alguns achados que se referem aos conteúdos de Matemática, à utilização de jogos, às estratégias usadas pela professora e à própria metodologia estudada.

Palavras-chave: Ensino e aprendizagem. Alfabetização matemática. Lógica do Cálculo.

\footnotetext{
${ }^{1}$ Mestre em Educação pela Universidade La Salle. Gestora no Colégio São Francisco de Assis. Endereço para correspondência: Av. Victor Barreto, 2288, Canoas/RS. carlaribeirocamargo@yahoo.com.br

${ }^{2}$ Doutora em Educação pela Universidade La Salle. Professora do curso de Pedagogia no Centro Universitário Cesuca. Especialista em Educação Básica na Secretaria Municipal de Educação de Canoas. Endereço para correspondência: Av. Victor Barreto, 2288, Canoas/RS. gabybonotto@gmail.com

${ }^{3}$ Doutora em Educação pela PUCRS. Professora do Programa de Pós-Graduação em Educação da Universidade La Salle. Endereço para correspondência: Av. Victor Barreto, 2288, Canoas/RS. vera.felicetti@unilasalle.edu.br
} 


\title{
Matter management and class management in Mathematics teaching: a perspective on the "logic of calculation" methodology
}

\begin{abstract}
This article has the goal of which is to investigate aspects of the development of teaching mathematics in the first year of Basic Education, based on the application of the "Logic of Calculation" methodology (SIMONS, 2013). This study is qualitative in nature, using a case study as the method. The data collection took place in a private school in the city of Canoas (RS), through in loco observation as well as a semi-structured interview with the teacher of the observed class. The data analysis was carried out using the technique of discourse textual analysis. The corpus analysis, composed of the observations and the interview with the teacher, resulted in two categories: Subject Management and Class Management. Based on this categorization, some findings were obtained with respect to content in Mathematics, using games, the strategies used by the teacher and the methodology studied.
\end{abstract}

Keywords: Teaching and learning. Mathematical literacy. Logic of Calculation.

\section{Gestión de materias y gestión de clases en la enseñanza de las Matemáticas: una perspectiva sobre la metodología de la "lógica del cálculo"}

\begin{abstract}
Resumen
Este artículo es un extracto de una tesis de maestría, y tiene como objetivo investigar aspectos del desarrollo de la enseñanza de las Matemáticas en un 1er año de educación básica a partir de la aplicación de la metodología "Lógica del Cálculo" (SIMONS, 2013). El estudio tiene un carácter cualitativo, optando por la técnica del estudio de casos. La recolección de datos se realizó en un colegio privado de la ciudad de Canoas (RS), mediante observación presencial y también a través de una entrevista semiestructurada con el docente de la clase observada. El análisis de datos se realizó con base en la técnica de análisis textual discursivo. El análisis del corpus, constituido por las observaciones y la entrevista con el docente, generó dos categorías: Gestión de Materias y Gestión de Clases. De esta categorización se obtuvieron algunos hallazgos que hacen referencia a los contenidos de Matemáticas, el uso de juegos, las estrategias empleadas por el docente y la metodología estudiada.
\end{abstract}

Palabras clave: Enseñanza y aprendizaje. Alfabetización matemática. Lógica de Cálculo.

\section{Introdução}

Muito fala-se em alfabetização, com ênfase na leitura e na escrita, porém também é necessário falar sobre alfabetização matemática. Esta é tão relevante quanto a leitura e a escrita e necessita ser percebida e trabalhada com o mesmo esmero, pois um aluno somente estará alfabetizado quando, além de ler e escrever, souber resolver as situações matemáticas a ele apresentadas no seu cotidiano. 
eISSN: $2526-9062$

Sendo assim, a metodologia ou a forma como se ensina Matemática é uma temática a ser pesquisada e analisada no âmbito acadêmico.

Nessa perspectiva, este artigo tem como foco principal investigar a metodologia "Lógica do Cálculo", proposta por Simons (2013), em uma turma de $1^{\circ}$ ano do Ensino Fundamental. Na metodologia proposta pela autora o ensino da Matemática no primeiro ano do Ensino Fundamental tem como foco a construção e o desenvolvimento das estruturas de raciocínio e do pensamento lógicomatemático de forma lúdica e prazerosa.

Para Simons (2013), a metodologia apresenta atividades que favorecem o aparecimento das estruturas cognitivas e proporcionam a aquisição de habilidades com números, de forma que, ao final desta série, a criança estará pronta para compreender o sistema de numeração decimal e suas implicações, e ainda apresentará maior segurança e domínio da leitura e da escrita.

Sendo assim, a metodologia "Lógica do Cálculo" traz um aporte concreto bastante significativo, como os blocos lógicos e as matrizes lógicas, materiais que serão detalhados e mostrados mais adiante. Neste sentido, o objetivo deste artigo é investigar aspectos do desenvolvimento do ensino da Matemática em um $1^{\circ}$ ano do Ensino Fundamental a partir da aplicação da metodologia "Lógica do Cálculo" (SIMONS, 2013).

\section{A Lógica do Cálculo}

Observando-se que o ensino da Matemática está em constante mudança, é necessário que o professor esteja sempre atento às questões didático-metodológicas (SANTOS; MATOS, M. L.; SANT'ANA, 2021). A metodologia adaptada por Simons (2013) privilegia o "aprender a pensar", dando ênfase ao desenvolvimento do raciocínio lógico, apoiando-se, principalmente, nos estudos de Piaget relacionados à gênese do conhecimento e aos estágios de desenvolvimento cognitivo infantil. Fundamentada no Construtivismo piagetiano, a "Lógica do Cálculo" acredita que o conhecimento é fruto da interação do sujeito com o ambiente, sendo o desenvolvimento e a aprendizagem resultados da ação do homem com o ambiente (GOULART, 1993).

A partir disso, a metodologia busca a ação dos alunos sobre a Matemática da forma mais concreta possível, utilizando-se de jogos pedagógicos e atividades lúdicas. Simons (2013) enfatiza que o livro fará parte do registro, pois a criança irá aprender por intermédio do jogo. 
eISSN: $2526-9062$

A metodologia "Lógica do Cálculo" tem como norteador os estágios de Piaget (2007). Assim, levando em consideração que os alunos do $1^{\circ}$ ano do Ensino Fundamental possuem 6 ou 7 anos, podese entender que eles estão no estágio pré-operatório, sendo necessário que, para que evoluam para o próximo estágio, no caso o estágio operatório concreto, sejam trabalhadas as estruturas de pensamento. Essas estruturas são apresentadas e desenvolvidas em todo o livro Lógica do Cálculo 1 (SIMONS, 2013) e também mediante o material de apoio que acompanha a coleção.

No $1^{\mathrm{o}}$ ano do Ensino Fundamental os alunos trabalham o desenvolvimento do pensamento lógico utilizando como material basilar o kit de blocos lógicos, as matrizes lógicas e o livro didático, o último elaborado pela autora supracitada. Simons (2013) sugere que o trabalho se realize por meio de jogos e brincadeiras, da maneira mais prática possível, de forma que o raciocínio e o entendimento do aluno sejam reflexos de experiências lúdicas vivenciadas.

Antes de trabalhar o conteúdo no livro ou no caderno, a professora que foi observada durante as aulas de Matemática propõe os jogos com o kit de blocos lógicos. Esse kit é composto por 1 conjunto de blocos lógicos (48 peças), 1 cartela de atributos (símbolos utilizados para as atividades de classificação), 16 cartelas de bingo para blocos lógicos, 1 caixa com cartas de atributos, 1 caixa de sinais para sentenças lógicas (material para formar sequências lógicas), 5 dados com atributos dos blocos lógicos e quantidades, 2 árvores lógicas (atividade com desenho em forma de árvore que tem o objetivo de desenvolver as relações lógicas por meio de critérios como cor, forma, etc.) e 1 livro com indicação de 150 exercícios com blocos lógicos. A seguir, na Figura 1, apresenta-se os materiais complementares do kit de blocos lógicos utilizado na metodologia "Lógica do Cálculo 1".

Figura 1 - Materiais complementares do kit de blocos lógicos

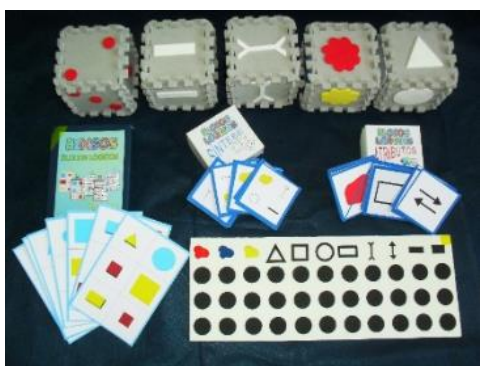

Fonte: Fonseca (2014).

Matriz lógica é um jogo de quadriculados que leva a criança a realizar diferentes organizações em seu pensamento lógico e a classificá-las de acordo com diferentes critérios. A caixa de matrizes lógicas é composta de 24 jogos, cada um deles com um grau de dificuldade diferente. O objetivo das 
eISSN: $2526-9062$

matrizes lógicas é desenvolver a classificação segundo diferentes atributos, desde o nível mais rudimentar, até alcançar a capacidade lógica e o pensamento reversível, momento em que a criança já consegue tornar suas análises móveis, percebendo o todo e as partes (SIMONS, 2003).

Segundo Simons (2013), os exercícios classificatórios são essenciais para a constituição do raciocínio flexível. A capacidade de classificar a partir de um único critério propicia sua aptidão de acordo com vários critérios ao mesmo tempo. Além disso, a análise de diferentes critérios leva o aluno a analisar, seja qual for a situação, sob diversos pontos de vista. Os blocos lógicos e as matrizes lógicas auxiliam na construção do raciocínio, dos níveis mais iniciais à capacidade lógica e o pensamento reversível, pois trabalham com a classificação segundo distintos atributos (SIMONS, 2013)

No livro de Simons e Oliveira (2003) são propostas atividades que desenvolvam noções de cor, forma e tamanho, identificação de atributos, igualdade e diferença, seriação, classificação, sequência lógica, correspondência termo a termo, inclusão de classes, intersecção de classes, identificação de quantidades, escrita de números, operações de adição e subtração, situaçõesproblema e geometria. Nas Figuras 2, 3, 4 e 5 destacam-se algumas atividades propostas no livro Lógica do Cálculo 1 (SIMONS, 2013).

A atividade exemplificada na Figura 2 propõe uma classificação com quatro critérios. Pela análise dos potes a criança deverá descobrir quais os critérios que devem ser observados para a separação destes. No exemplo, na primeira prateleira a classificação foi realizada com o critério de cor do pote; na segunda, potes com ou sem asa; na terceira, potes com ou sem desenho; e, na última prateleira, potes com ou sem pires. 
Figura 2- Atividade de classificação com quatro critérios

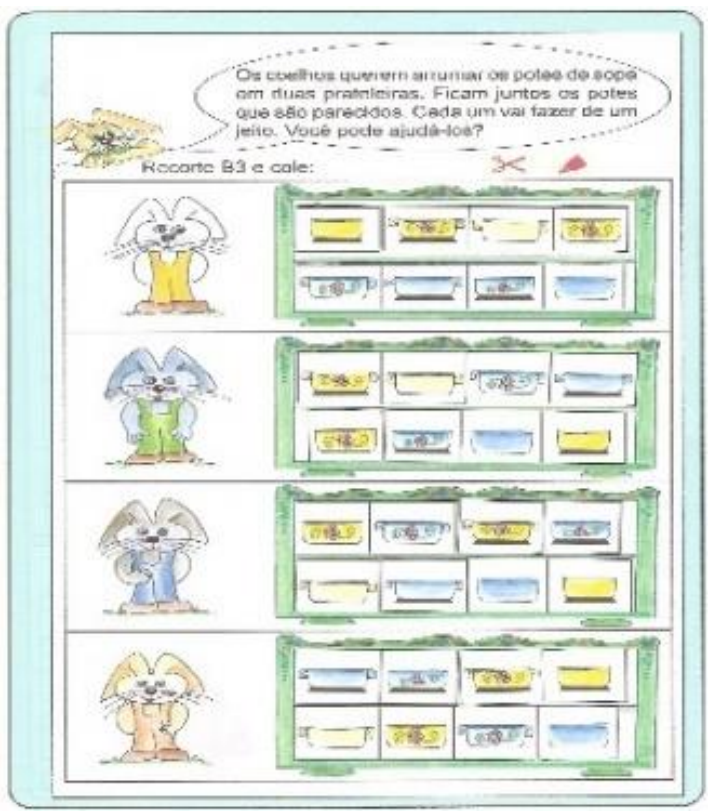

Fonte: Simons; Oliveira (2003, p. 65).
Figura 3 - Atividade de conservação e correspondência termo a termo

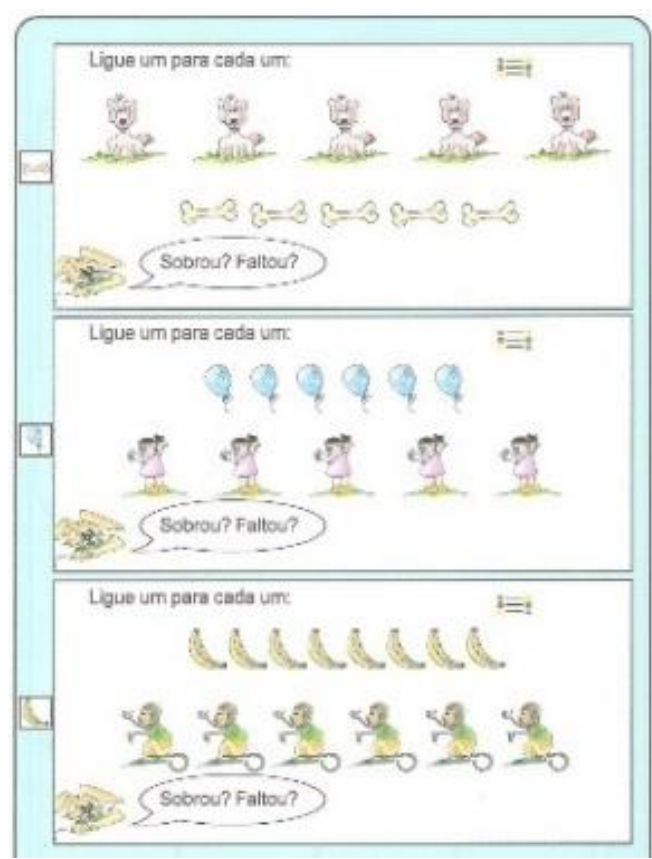

Fonte: Simons; Oliveira (2003, p. 29).

A atividade presente na Figura 3 exercita a compreensão da correspondência termo a termo bem como a noção de conservação. Esse raciocínio permitirá que a criança perceba que certas quantidades de elementos não se modificam, mesmo que estes estejam dispostos de maneira diferente no agrupamento.

Na Figura 4 apresenta-se uma atividade de seriação, pois a criança terá de ordenar as escadas de acordo com a altura e também com a sua espessura. Segundo Simons e Oliveira (2009), apenas uma criança que seriou anteriormente diversos elementos poderá realizar uma seriação numérica operatória com entendimento, e não apenas como sequência decorada, afinal o número é o representante simultâneo de uma classe (quantidades) e de uma série (ordenação numérica). Assim, as classificações e as seriações servem de base para a construção do número. 
Figura 4 - Atividade de seriação

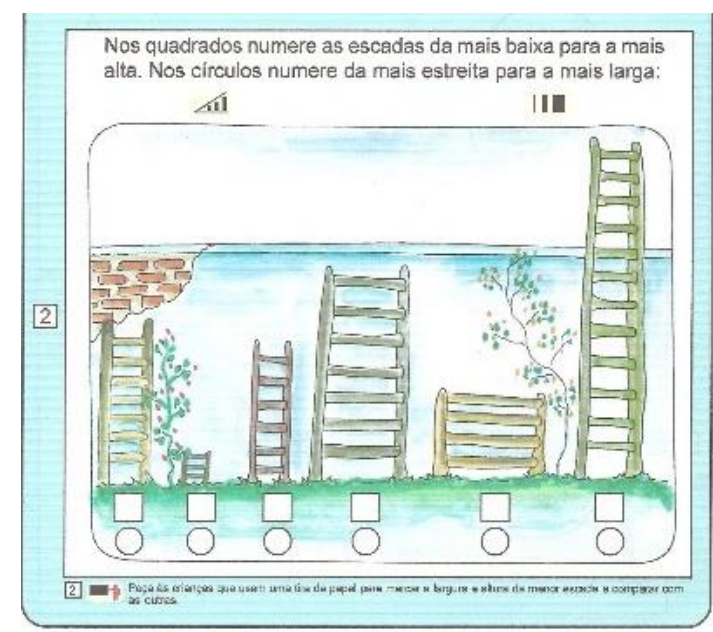

Fonte: Simons; Oliveira (2003, p. 162).
Figura 5 - Atividade de inclusão de classes

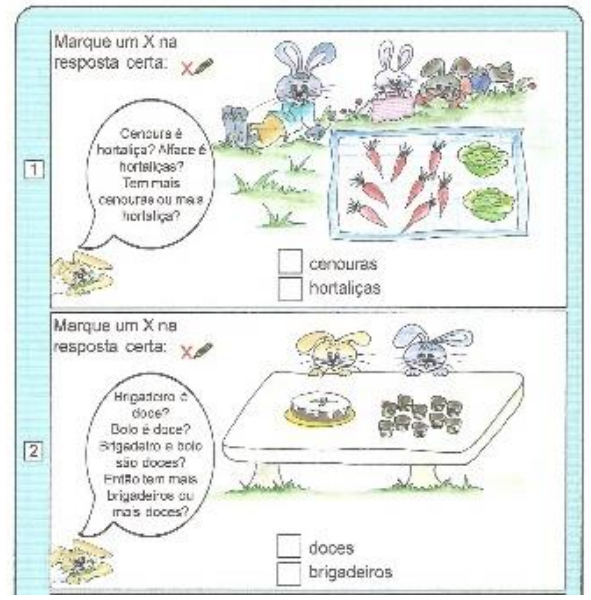

Fonte: Simons; Oliveira (2003, p. 161).

A atividade da Figura 5 refere-se à inclusão de classes. Analisando as imagens e refletindo sobre as questões propostas, a criança deverá chegar às relações de pertinência e inclusão, percebendo o significado de classe e de objetos reais.

No $1^{\circ}$ ano do Ensino Fundamental, segundo a proposta Lógica do Cálculo, as estruturas lógico-matemáticas de classificação, ordenação e conservação são o foco do trabalho, pois, segundo Piaget e Inhelder (1999), elas caracterizam o raciocínio lógico do nível operatório concreto, e são a base para a construção do número que, dentro dessa proposta, será o objetivo principal no $2^{\circ}$ ano do Ensino Fundamental.

De acordo com os conteúdos previstos no livro Lógica do Cálculo 1 (SIMONS, 2013), podese perceber uma grande diferença em relação aos conteúdos tradicionais estudados nas escolas no $1^{\circ}$ ano do Ensino Fundamental. A maior diferença refere-se ao fato de, geralmente, essas turmas focarem na construção do número, trabalhando já os conceitos de unidade, dezena e centena.

\section{Procedimentos Metodológicos}

Para responder ao problema de pesquisa - Como se dá o ensino da Matemática no $1^{\circ}$ ano do Ensino Fundamental de uma escola privada de Canoas, por meio da metodologia "Lógica do Cálculo" proposta por Ursula Marianne Simons? - em tela, utilizamos a abordagem qualitativa. Conforme Triviños (2008), a pesquisa qualitativa tem o ambiente natural como fonte direta dos dados e o pesquisador como instrumento-chave. Nesta investigação esse ambiente natural foi uma escola 
eISSN: $2526-9062$

particular da cidade de Canoas, no Rio Grande do Sul, na região metropolitana de Porto Alegre. Uma turma foi observada para desenvolver uma visão completa e minuciosa do funcionamento da metodologia "Lógica do Cálculo".

Na escola pesquisada estudam aproximadamente 1.600 alunos - crianças de classe média, boa parte delas pertencentes ao Ensino Fundamental -, sendo considerável parcela dos pais trabalhadores autônomos.

Essa escola possui seis turmas de $1^{\circ}$ ano, sendo 1 no turno da manhã e 5 no turno da tarde. As turmas de $1^{\circ}$ ano dessa escola têm em torno de 25 alunos, e são compostas por meninos e meninas de forma equilibrada, ou seja, cada turma possui, praticamente, o mesmo número de meninos e de meninas. Boa parte dessas crianças permanece o dia todo na escola, pois participam do Turno Integral (Tuin). No período inverso da aula em que os alunos ficam na escola são desenvolvidas atividades orientadas, como recreação, tempo para a realização dos temas e reforço escolar.

Uma das cinco turmas do vespertino foi observada com objetivo de verificar o funcionamento da metodologia "Lógica do Cálculo". Deste modo, houve um acompanhamento sistemático do trabalho docente realizado bem como da participação dos alunos na aula.

A turma observada foi sugerida pela direção da escola, pois a professora regente apresenta conhecimento da proposta, posto que a mesma realizou o curso de formação da metodologia adotada, o qual foi oferecido pela escola no ano de 2013; além disso, o horário das aulas de Matemática ministradas pela docente concilia com o horário disponível para a observação.

Do ponto de vista técnico, a presente pesquisa trata-se de um estudo de caso. Yin (2001) afirma que o estudo de caso se adapta às pesquisas em que o investigador é confrontado com situações complexas e procura respostas para o "como?" e o "por quê?". A observação estruturada foi usada, pois, segundo Lüdke e André (1986), é aquela que se realiza em condições controladas para se responder a objetivos anteriormente definidos, requer planejamento e necessita de operações específicas para o seu desenvolvimento.

Como ferramenta metodológica para o registro das observações foi utilizado um Diário de Campo. Este foi escrito à mão, que registrava em um caderno tudo o que acontecia em sala de aula durante a observação in loco, anotando todos os detalhes possíveis, procurando observar e apontar o que estava explícito e implícito nas situações. 
eISSN: 2526-9062

A entrevista semiestruturada foi gravada e transcrita na íntegra e, posteriormente, encaminhada à entrevistada para que fizesse a validação do conteúdo. Após essa validação, foi feita a análise desses dados.

A verificação dos dados foi realizada por meio da análise textual discursiva sugerida por Moraes e Galiazzi (2012), prosseguindo para as etapas de unitarização, categorização, construção do metatexto e captação do novo emergente. As categorias emergentes foram Gestão da Matéria e Gestão da Classe.

\section{Gestão da Matéria no Ensino da Lógica do Cálculo}

Segundo Fayol (2012), no início do século 20 aconteceu a expansão dos estudos em relação ao entendimento sobre o que significa entender e apropriar-se do número. Como consequência, percebeu-se o descompasso entre o desenvolvimento da criança e os programas de ensino. Surgiram, então, duas possibilidades de intervenção. A primeira consistiu em adiar a introdução de algumas noções e habilidades com o objetivo de adaptar a dificuldade ao grau de desenvolvimento da criança; já a segunda propôs modificações no ambiente e nas intervenções, de forma que estas acelerem a aprendizagem de saberes e habilidades.

A metodologia "Lógica do Cálculo" optou pela primeira possibilidade, acreditando que a adaptação do currículo ao grau de desenvolvimento da criança é que trará uma aprendizagem efetiva ao educando.

Durante as observações in loco foi possível perceber que as estruturas de classificação, seriação, correspondência termo a termo, sequenciação, inclusão de classes e intersecção, foram trabalhadas intensamente por meio dos inúmeros exercícios existentes no livro didático, como também por intermédio de alguns jogos ou atividades concretas.

Em vez de apenas ouvir e repetir o que o professor faz, a criança precisa agir e atuar sobre o conhecimento, reelaborando-o e reinventando-o ao seu modo. Esse experienciar a levará à compreensão de sua ação, ou seja, à aprendizagem. Se não houver entendimento não haverá aprendizagem, e sim a automatização de exercícios e respostas. O jogo é uma possibilidade de aprendizagem, pois “A aprendizagem se realiza através da ação, de dentro para fora. Para que haja aprendizagem significativa, deve haver participação efetiva da criança” (DANTE, 1996, p. 35). 
eISSN: $2526-9062$

Nas aulas observadas, em que a professora desenvolveu atividades com jogos, foi possível verificar a autonomia dos alunos com relação à aprendizagem, pois, enquanto jogavam, colocavam também em jogo os seus conhecimentos, levantavam hipóteses e as testavam, trocavam ideias com os colegas e participavam efetivamente da construção de seu conhecimento mediante a ação.

Percebe-se que o foco desta metodologia é o aprender por intermédio do jogo, do concreto e da manipulação de materiais. Mediante a fala da professora, retirada de sua entrevista, nota-se o entendimento da mesma em relação ao lugar que o jogo ocupa nessa metodologia: "Eu penso que o mais importante é o brincar, é mostrar o conteúdo de forma lúdica, é deixar eles tocarem nos objetos, manusearem os jogos. Eu acho que isto é muito importante, porque é este brincar, direcionado, que prepara e fornece a base para a criança aprender e desenvolver as atividades."

Dante (1996) enfatiza que o jogo, enquanto brincadeira, é atividade inerente a qualquer criança, e, por isso, considera-o uma importante estratégia de ensino, pois ele estimula a interação, a participação, a curiosidade e a criatividade. Com o jogo a criança é desafiada a pensar e a agir; assim, aprende brincando, o que lhe causa prazer, ao contrário do sentimento de aborrecimento causado por atividades rotineiras.

O trabalho com os jogos na sala observada causava muito prazer às crianças, de forma que elas associavam os jogos à Matemática e ambos ao sentimento de prazer e alegria. Em vários momentos, durante as observações, percebeu-se a alegria dos alunos em virtude dos jogos, pois sempre que a professora anunciava que iam jogar eles se entusiasmavam e, prontamente, deixavam tudo de lado para se dedicarem ao jogo com muito empenho. O início dos jogos na turma era marcado por aplausos e pela vibração dos alunos; já no encerramento lamentavam terem de parar, e pediam em coro para "jogar mais um pouquinho".

De acordo com a metodologia "Lógica do Cálculo", no $1^{\circ}$ ano do Ensino Fundamental o jogo assume o papel de destaque e é considerado o principal meio que deve ser utilizado pelo professor para o ensino e a aprendizagem do aluno. Pelas observações pode-se notar que a utilização do jogo como recurso didático é bem-vista pelos alunos, que vibram e se dedicam intensamente a cada brincadeira, e também pela professora, conforme apontado na entrevista realizada: "Gosto muito de trabalhar com essa Matemática! Adoro trabalhar os jogos! Piaget diz que a criança de 6 anos precisa do concreto pra aprender, precisa manipular, tocar! E é através do jogo que podemos proporcionar 
eISSN: $2526-9062$

isto à criança”, ou seja, as operações mentais desenvolvidas pelas crianças por meio da metodologia proposta.

Pensando o jogo dentro do contexto educacional e situando-o em objetivos mais amplos, Friedmann (1996) explica que a escola é um agente de transformação da sociedade e que, nesse sentido, deve considerar as crianças seres sociais e trabalhar para que elas se integrem de forma construtiva na sociedade; além disso, deve ter a preocupação de propiciar às crianças um desenvolvimento integral (cognitivo, afetivo, linguístico, social, moral e físico-motor), porém, para que este desenvolvimento integral possa ser concretizado, devem ser levados em consideração os interesses e as necessidades dos educandos, e é neste espaço que se insere o jogo, uma vez que a aprendizagem depende, em grande parte, da motivação da criança. Assim, “[...] trazer o jogo para dentro da escola é uma possibilidade de pensar a educação numa perspectiva criadora, autônoma, consciente" (FRIEDMANN, 1996, p. 57).

Nos momentos de observação in loco foi possível perceber a posição em que o jogo, ou o livro, coloca o aluno. Nas atividades do livro o professor tem um papel mais ativo e dirige a aprendizagem dos alunos; nos momentos de jogos os alunos são o centro do processo; eles são quem gerencia suas aprendizagens mediante a ação sobre os objetos. Nas observações realizadas nesta pesquisa, como também na entrevista com a professora, foi possível perceber a importância atribuída pela docente ao jogo, pois, nos momentos utilizados, os jogos estavam em harmonia com os conteúdos trabalhados, e, na maioria das vezes, foram usados para o ensino e a aprendizagem de um novo conteúdo ao aluno, antecedendo o emprego do livro, conforme é sugerido na metodologia em estudo.

Em relação à frequência com que a professora proporciona os jogos aos alunos, observou-se que ainda é possível evoluir, uma vez que, das 84 aulas observadas, 62 foram trabalhadas no livro, 18 com jogos, 3 com folha xerocada e 1 com massinha de modelar.

Partindo do pressuposto de que é pela manipulação dos jogos que o aluno irá aprender, 18 aulas com jogos é pouco; deveria, ao menos, equivaler à metade das aulas. A esse respeito, Simons (2013) sugere que o jogo seja realizado uma ou duas vezes na semana, conforme a necessidade de cada turma, e ele somente poderá ser dispensado após a visualização de que a aprendizagem foi concretizada; aí sim será o momento da sistematização dos conteúdos por meio do registro escrito, ou seja, por intermédio do uso do livro didático. 
eISSN: $2526-9062$

$\mathrm{Na}$ entrevista realizada com a professora, esta relata que percebe a necessidade de aumentar o isso de jogos:

\begin{abstract}
Trabalhar com os jogos é muito bom, pena que a gente tem muita coisa pra trabalhar, eu penso que seria muito importante se a gente pudesse trabalhar os jogos duas vezes na semana, eu trabalho uma vez na semana e acho que é pouco, mas também se a gente fica só nos jogos, atrasa o livro, mas uma vez só na semana é pouco, precisava jogar mais. Jogar nunca é demais!
\end{abstract}

$\mathrm{Na}$ fala da professora é possível perceber a sua preocupação em realizar todas as atividades do livro no tempo certo, concluindo-as ao final do ano letivo, o que é uma preocupação plausível, pois sabe-se que nas escolas particulares a cobrança pela utilização dos livros é grande por parte dos pais.

Simons (2013), entretanto, afirma que o uso dos jogos contribui também para a agilização do trabalho no livro, pois a criança que já aprendeu o conteúdo na prática e, portanto, domina o conhecimento, terá facilidade nas atividades, resolvendo mais rapidamente os exercícios. Deste modo, as crianças que aprendem pela prática geralmente preenchem o livro com mais facilidade, rapidez e eficiência do que aquelas que não jogaram e não consolidaram o conhecimento por meio da prática.

O jogo, além de ser responsável pela aprendizagem do aluno, também colabora para a eficiente utilização do livro didático, o qual é destinado à síntese e sistematização dos conteúdos. Após a exploração do tema pelo professor e o brincar da criança, todavia, o livro poderá ser preenchido, momento que servirá para a interiorização do conteúdo (SIMONS; OLIVEIRA, 2009).

Pelas observações em sala de aula, bem como mediante à entrevista com a professora, foi possível perceber que existe esta vontade de mudar e fazer o melhor de acordo com o que a metodologia propõe, ou seja, jogar mais. A reorganização do plano da disciplina, visando a intensificar o uso dos jogos e dar um equilíbrio entre a quantidade e a variedade de atividades, é fundamental para melhor qualificar a metodologia em ação, de modo que se mantenham os princípios metodológicos da Lógica do Cálculo.

No emprego do livro didático a professora mantém a mesma estratégia: pede que um aluno leia o enunciado, e, após, retoma o mesmo, explicando-o minuciosamente com suas palavras, ressaltando aspectos importantes, fazendo comparações e dando exemplos no quadro, ou com o próprio corpo, para, posteriormente, incentivar os alunos à realização da atividade. Primeiramente a professora explica a atividade para o grande grupo, e, logo, passa a atendê-los individualmente. 
eISSN: $2526-9062$

Gauthier et al. (2013) explicam que o sequenciamento sistemático do conteúdo contribui para o êxito dos alunos, pois um conteúdo que é explicado passo a passo, de maneira completa, incluindo exemplos, tende a ser mais bem compreendido, facilitando a aprendizagem e contribuindo para a motivação dos alunos. Além disso, os autores supracitados evidenciam que conteúdos organizados e apresentados de maneira lógica e com suficiente redundância, de forma que reforce regras e conceitos importantes, colaboram para o melhor entendimento do aluno.

As observações in loco também demonstraram que a professora investe mais tempo ensinando ao grande grupo de alunos do que individualmente, o que, segundo Gauthier et al. (2013), é associado positivamente à aprendizagem, pois, em sua pesquisa, as turmas em que a aprendizagem é elevada apresentam menos atividades independentes e individuais. É importante salientar, no entanto, que as atividades individuais também são importantes e devem ser previstas no planejamento do professor, uma vez que esse é o momento de consolidar as aprendizagens de forma autônoma. Gauthier et al. (2013, p. 209) reiteram esta ideia, afirmando também que "os professores eficientes propõem exercícios individuais em classe".

Simons e Oliveira $(2009$, p. 2) salientam: “A aprendizagem é tratada neste livro como uma aquisição individual e, portanto, depende do ritmo de cada um, mas o grupo deve ser solicitado a todo o momento para colaborar com o crescimento individual e coletivo". Parece-nos evidente que o manejo da professora em relação à condução das atividades é produtivo e eficaz, pois ela mantém o equilíbrio entre a orientação ao grande grupo e no individual, conforme é indicado na teoria da metodologia em estudo.

Outro ponto de destaque na metodologia da professora refere-se à maneira como frequentemente questiona os alunos. Conforme apresenta um exercício ou conteúdo, a docente questiona as crianças para que cheguem à aprendizagem. Ela procura não dar respostas prontas, incentivando o raciocínio dos alunos para que eles encontrem o resultado sozinhos; para isto, dá exemplos, ampara com pré-requisitos, realiza associações e retoma conceitos e aprendizagens.

Os exemplos, analogias e comparações são bastante utilizados pela professora em suas aulas, estratégias que, segundo Gauthier et al. (2013), estão significativamente ligadas ao bom desempenho dos alunos. A prática efetiva do uso de indagações realizada pela professora também foi bastante empregada, com o objetivo de manter a atenção do grupo e para a verificação da aprendizagem. Ao fazer perguntas com o intuito de que a turma permanecesse atenta, o professor desperta no aluno a 
eISSN: $2526-9062$

sensação de responsabilidade pela aprendizagem, pois, nesta situação, eles percebem que a qualquer momento podem ser chamados a responder, a dar a sua opinião (GAUTHIER et al., 2013).

Nesse sentido, a indagação da professora oportuniza, mais uma vez, a verificação da aprendizagem, possibilitando que se certifique de que as habilidades necessárias foram apreendidas; além disso, produzirá o sentimento de tarefa cumprida a todos os envolvidos no processo de ensino e aprendizagem. Gauthier et al. (2013) afirmam que é reconhecida a importância de se fazer perguntas aos alunos em diversos momentos do processo de ensino, seguidas de retroações corretivas; inclusive salientam que professores eficientes realizam uma pergunta a cada dois minutos, o que nos leva a perceber que uma aula eficiente é permeada de inúmeras indagações.

Sobre o papel do professor, Simons e Oliveira (2009, p. 15) enfatizam: “O orientador, por sua vez, deve ter o cuidado de não dar as instruções prontas para a criança, mas questionar, até que ela mesma encontre as soluções. Levar a criança a pensar, tirar conclusões, é o papel fundamental do educador". Esta preocupação em não dar as respostas prontas aos alunos, mas questioná-los e leválos a pensar, é bastante evidente na prática da professora e, portanto, demonstra consonância com a fundamentação da proposta.

Durante diversos momentos da aula, seja na explicação de conteúdos ou exercícios ou na hora de jogos ou atividades no caderno, mediante sua fala a professora instiga a curiosidade dos alunos e, com isto, faz com que as crianças se motivem a encontrar o resultado. Os excertos a seguir demonstram as falas utilizadas pela professora para o incentivo aos alunos. "[...] Qual é o segredo? [...] Quero ver quem consegue fazer o próximo exercício! [...] Agora tenho um desafio! [...] Vou dar uma pista, vamos ver se vocês descobrem! [...] Quero ver quem vai descobrir! [...] Quem gosta de desafio?"

Proporcionar que a criança pense é um processo dinâmico e complexo, e, para isto, o professor precisa manter a motivação de seus alunos e incentivar a curiosidade - característica inata à criança - que pode ser um ótimo recurso para garantir um alto nível de motivação bem como trazer resultados muito significativos (SIMONS; OLIVEIRA, 2009).

Em suas aulas, outra estratégia bastante empregada pela professora é suscitar a dúvida, desafiando os alunos a descobrirem respostas e buscar conhecimentos. Sentindo-se desafiados e com o desejo de mostrar suas potencialidades, eles motivam-se e se empenham em fazer o melhor e, assim, responder ao esperado pela professora. Outro ponto que chamou a atenção durante as observações 
eISSN: $2526-9062$

em sala de aula foi a ênfase dada pela professora ao vocabulário técnico da Matemática. A todo o momento ela utilizava termos técnicos, o que era perfeitamente aceito e bem-elaborado pelos alunos, ou seja, o emprego destes termos pelos educandos já era frequente. Simons e Oliveira (2009) sugerem o uso dos termos técnicos pelo professor, pois é pela sua visualização adequada e constante que as crianças irão se acostumando com eles e descobrindo seus significados. Os autores salientam, porém, que a cobrança desses termos não deve ser exigida da criança, pois a distinção entre os significados de alguns deles é extremamente abstrata, o que exigiria do educando um raciocínio acima de seu nível cognitivo nesse âmbito escolar.

\section{A Gestão da Classe na Metodologia Lógica do Cálculo}

$\mathrm{Na}$ análise dos dados referente à gestão da classe, alguns procedimentos destacaram-se fortemente na ação da professora, como a rotina sistemática que é aplicada nas aulas - rotina entendida aqui como uma organização contínua, um padrão equilibrado de comportamentos e não como mera repetição -, a organização constante, de forma a inculcar nos alunos esta organização e o incentivo de hábitos e atitudes necessários ao bom convívio com os demais alunos bem como com o planeta, a orientação dirigida passo a passo para a aprendizagem dos alunos, o incentivo da atenção constante ao professor e às atividades e a circulação efetiva da professora pela sala para atender os alunos, oferecendo-lhes retroações imediatas.

Um dos pontos de maior destaque, e por isto será desenvolvido primeiramente, é a rotina sistemática adotada pela professora em suas aulas. Segundo Gauthier et al. (2013), as rotinas consistem na automatização de procedimentos objetivando o controle e a coordenação de comportamentos em situações específicas. Com as observações in loco foi possível perceber que todos os momentos da aula eram marcados por rotinas, o que colocava o aluno em lugar de tranquilidade, pois já sabia o que esperar em cada momento da aula. A sequência de instruções ofertada pela professora na realização das atividades era uma prática constante, e ocorria de maneira muito similar em todas as aulas, o que proporcionava ao aluno, além de tranquilidade, a possibilidade da autonomia e da autoria, pois essa rotina oferecia a ele prever certas coisas e se adiantar nelas.

Gauthier et al. (2013) mencionam que a rotinização das atividades ajuda a manter a ordem na classe, pois atenua a indeterminação da situação da aprendizagem e reduz a ocorrência de interrupções. Os alunos já conhecem a sequência das atividades, e, além disso, a utilização das rotinas libera tempo e energia para outras atividades relacionadas à sua aprendizagem. 
eISSN: $2526-9062$

Nas aulas que eram trabalhadas com o livro, alguns alunos ajudantes do dia retiravam os mesmos do armário e distribuíam aos colegas. Logo, a professora explicava sobre o que iam trabalhar, indicando a página que deveriam abrir; além disso, escrevia no quadro a página para que os alunos pudessem visualizar o numeral, assim como a data, para que todos a escrevessem acima na página trabalhada. Às vezes algumas crianças pediam para escrever o número da página no quadro antes mesmo de a professora verbalizar o que iriam trabalhar, o que evidencia que os alunos internalizaram a rotina, e, mais do que isto, que esta rotina, proposta pela professora, servia de modelo para eles, que a imitam em suas atitudes.

A leitura dos enunciados pelas crianças e a posterior explicação da professora eram habituais, e, somente depois, os alunos eram liberados para a realização das atividades sozinhos. A professora circulava entre os estudantes fornecendo-lhes esclarecimento às dúvidas e correção individual e imediata das atividades. As correções eram feitas diariamente logo após o término das atividades, e os alunos sabiam que somente poderiam guardar o livro novamente no armário após a correção da professora.

As próprias atividades do livro encaminhavam para a rotinização, pois os exercícios propostos trabalhavam várias vezes, o mesmo fundamento, porém, por meio de mecanismos diferentes, essa solicitação à repetição de um fundamento, de outra forma, predispunha o aluno a familiarizar-se com as atividades, o que levava à rotina, mas não à massificação, posto que os exercícios eram propostos de maneiras diferentes.

No caderno de aula a professora mantinha a rotina de pintar uma linha do caderno a cada aula que começava, dividindo a aula do dia anterior com a que ocorria, o que os alunos chamavam de linha divisória. Após, escreviam a data para, depois, começarem os registros do dia. Em virtude desta organização sistemática, alguns alunos já vinham de casa com a linha pintada e a data escrita, e, com prazer e alegria, verbalizavam que já sabiam o que tinham de fazer, que já estavam prontos, até mais adiantados que a professora.

Nas atividades com jogos o que chamou mais atenção foi a rotina de organização que era mantida, desde a formulação dos grupos para poderem jogar até o momento de como guardar esses materiais. Essa rotina de intensa organização é outro ponto de destaque na metodologia da professora. Ao gerenciar a turma, todos os detalhes passam pelo crivo da docente, que, logo, orienta os alunos para que se organizem, seja com o livro, o caderno, os jogos ou com os seus materiais de uso pessoal. 
eISSN: $2526-9062$

É costume da professora, enquanto caminha entre os alunos, pedir que eles alinhem as mesas e cadeiras, que sentem corretamente, que reúnam alguns itens que estejam fora do lugar, que arrumem os materiais de uso individual sobre a mesa da melhor forma possível, deixando somente o necessário para a atividade.

Ao usarem o livro, a professora sugere a melhor forma de trabalho - dependendo da atividade, com o livro aberto ou fechado. É intensamente frisado pela professora que as crianças aprendam a se organizar com o livro. Ela orienta frequentemente sobre os recortes do livro, que devem ser retirados dos anexos, um a um, e colados imediatamente na atividade para que não se percam peças. $\mathrm{O}$ momento de guardar os livros no armário também passa pela orientação da professora, que instrui os alunos para que organizem os mesmos com as molas uma para cada lado, para que a pilha de livros não se desequilibre.

O uso do caderno é acompanhado pela docente, que solicita a todo o momento capricho e organização, e orienta quanto ao uso dos parágrafos, dobradura e colagem de folhas de xérox dentro das margens e atividades que envolviam pintura. Os momentos de jogos são muito organizados. Ela fala sobre a atribuição de cada aluno, distribuindo os papéis e, posteriormente, cobra que estes respeitem as regras dos jogos; ela as explica com detalhes, organizando quem começa, o lado que inicia, etc.

Outro procedimento muito utilizado por ela no gerenciamento da turma era o ato de circular em sala de aula, tanto para o acompanhamento da aprendizagem quanto para o controle da disciplina na turma. Em todas as observações a professora esteve em constante movimento entre os alunos. Geralmente orientava a atividade no grande grupo, dando exemplos ou sugerindo algum exercício, e logo incentivava a realização individual pelos alunos, que era acompanhada por ela, pois, enquanto as crianças faziam as atividades, a docente circulava de mesa em mesa, orientando-as.

Consoante Gauthier et al. (2013), o ato de supervisionar o trabalho dos alunos circulando em sala deve ser incentivado, posto que o contato com o professor durante o trabalho individual aumenta em aproximadamente $10 \%$ o nível de desempenho dos alunos, porque durante esta prática os professores conseguem colher e distribuir diversas informações que lhes permitem fazer perguntas, dar pequenas explicações e fornecer retroações e reforços necessários; além disso, a circulação do docente e a sua constante presença próxima ao aluno, imprime à classe um clima de segurança e relaxamento. 
eISSN: $2526-9062$

A movimentação em sala de aula é imprescindível ao professor, porém, segundo Lemov (2011), não basta circular em sala aleatoriamente; é importante que o professor possa mover-se estrategicamente em razão de suas necessidades pedagógicas, seja para a instrução sobre a matéria ou para a orientação de comportamentos desejáveis. Resumindo, não basta circular, é preciso interferir enquanto circula.

$\mathrm{Na}$ entrevista foi perguntado à professora o motivo da constante circulação em sala de aula: "Eu gosto de ter o feedback da criança; é uma maneira de saber se ela aprendeu ou não, porque se não aprendeu eu já dou uma orientada, já direciono a aprendizagem." Nas observações in loco foi possível perceber que a professora utilizava a circulação com o objetivo de acompanhar a aprendizagem dos alunos ou, ainda, para reprimir algum comportamento indesejado. No primeiro caso, as interferências aconteciam por meio de incentivos verbais, indagações e retroações; já as intervenções relacionadas ao comportamento se davam de forma verbal, chamando pelo nome do aluno, ou pedindo a ele que retornasse à atividade. As interferências também ocorriam de forma não verbal, por intermédio de toque sutil no ombro do aluno quando deveria se sentar, ou um olhar de desaprovação para alguma atitude.

As questões de indisciplina e do cumprimento das regras eram tratadas pela professora enquanto circulava, e são estas questões que discutiremos na sequência. No início do ano ela e os alunos conversaram sobre as regras de convivência que deveriam ter em sala, formulando um grande cartaz com os "combinados" da turma. O cartaz está exposto na sala e a todo o momento é relembrado por ela e pelos próprios alunos.

Para cada regra foi estabelecido um número; assim, basta a docente falar "Regra 2", por exemplo, que os alunos já sabem do que se trata. As regras 2, 5 e 10, respectivamente correspondentes a ouvir a professora, realizar as atividades e ser amigo de todos, foram as mais utilizadas e verbalizadas nos períodos de observação. Geralmente enquanto circula entre os alunos a mesma observa se eles estão seguindo as regras e vai solicitando que cumpram o estabelecido: "Regra 5!" verbaliza a professora quando observa que alguns alunos estão dispersos, deixando de realizar as tarefas.

Gauthier et al. (2013) mencionam que uma boa gestão de classe é baseada na antecipação dos professores em relação à trajetória provável das atividades de sala de aula e no conhecimento das consequências dessas mesmas atividades sobre as situações de aprendizagem. Relembrar o 
eISSN: $2526-9062$

combinado pela professora reafirma aos alunos o que ela espera dos mesmos, o que corrobora as ideias de Gauthier et al. (2013, p. 251), que asseveram: "O desempenho dos alunos e seus comportamentos são influenciados pelas mensagens que recebem a respeito daquilo que se espera deles”. Essa prática adotada pela professora evita comportamentos indesejados, e, portanto, previne futuras punições pela ocorrência dos mesmos.

Vasconcellos (1994) salienta que a disciplina não está pronta; ao contrário, é uma construção coletiva, efetuada por alunos e professores. Este autor destaca que é preciso vislumbrar as discussões sobre disciplina sob outra ótica, pois o seu cerne não está no comportamento do aluno, ou no desejo do professor, e sim na organização do trabalho coletivo em sala de aula, com foco na construção do conhecimento.

Gauthier et al. (2013) afirmam que as intervenções bem-sucedidas junto aos alunos são, geralmente, feitas em particular. Elas são breves, indicam o comportamento adequado e informam as eventuais consequências da repetição dos comportamentos inadequados. As correções individuais ocorreram poucas vezes em sala de aula. Somente em casos extremos, e que tumultuavam a aula, a professora chamava os alunos para uma conversa em particular. Na maioria das vezes, circulando e supervisionando ativamente na sala, a professora parecia prever comportamentos indesejáveis e, antes que ocorressem, empregava medidas para preveni-los, como um toque na mesa mostrando a atividade, contato direto com os olhos, gestos de silêncio e atenção, ou, ainda, rápidas interferências verbais como silêncio!, psiu! ou chamando pelo nome.

As estratégias lúdicas utilizadas pela professora, que provocam o imaginário das crianças, são muito bem-aceitas pelos alunos, e trazem ótimos resultados, pois, além de parecerem uma brincadeira, trabalham com a fantasia, o que é foco de interesse das crianças nesta faixa etária de 6 anos; isso retoma a concentração, aspecto fundamental para a realização das atividades.

Em virtude dos jogos utilizados na disciplina de Matemática, era bastante comum a movimentação das mesas pelos alunos nessa turma. Apesar da orientação da professora para que levantassem as mesas evitando o barulho, sempre ocorria certo tumulto nesses momentos. A professora, então, intervia dizendo: "Levantem as classes, não arrastem! Têm outras turmas trabalhando! Não podemos fazer tanto barulho!" Com esta fala a professora demonstra que devemos ser solidários e pensar nas demais pessoas; que nossa liberdade vai até o ponto em que começa a liberdade do outro, o que torna o respeito pelo próximo indispensável. 
eISSN: $2526-9062$

Outra atitude frequentemente realizada pela professora é a observação ativa e atenta sobre a limpeza e a organização da sala de aula. Enquanto circula entre os alunos e orienta-os quanto à aprendizagem, também vai orientando-os em relação aos papéis que estão caídos no chão, pedindo que as crianças os juntem e os coloquem na lixeira; também solicita que alinhem as mesas e reúnam os materiais escolares jogados no chão.

\section{Considerações Finais}

A partir deste estudo buscou-se responder à seguinte problemática investigativa: Como se dá o ensino da Matemática no $1^{\circ}$ ano do Ensino Fundamental de uma escola privada de Canoas, por meio da metodologia "Lógica do cálculo" proposta por Ursula Marianne Simons? Com isso, surgiram duas categorias: Gestão da Matéria e Gestão de Classe.

Em relação à Gestão da Matéria, é importante salientar que a metodologia "Lógica do Cálculo" se refere às estruturas de raciocínio. Outro fator de destaque, e que está intimamente ligado aos objetivos desta pesquisa, é a utilização do jogo neste processo. É possível afirmar que o jogo é o cerne desta metodologia e o principal instrumento para o desenvolvimento da aprendizagem, pois, retomando Piaget (2007), a criança de 6 anos aprende por meio do concreto, da ação e da manipulação do real. Nesse sentido, o jogo é o mediador empregado para que a aprendizagem se efetive.

Em relação à Gestão da Classe destacaram-se atitudes, regras e manejos utilizados pela professora, necessários ao bom desenvolvimento da aula, como a rotina constante e a organização sistemática, a circulação efetiva da professora em sala de aula, acompanhada de retroações e intervenções preventivas, o incentivo em relação aos hábitos e atitudes necessários às relações pessoais e à solidariedade, como também a alegria e a amorosidade expressa pela docente em sua prática.

Por fim, destaca-se que os procedimentos, técnicas e manejos usados pela professora para gerenciar a matéria e também a classe, embora nem todos estivessem prescritos nas bases teóricas da metodologia, são estratégias que potencializaram a proposta da metodologia "Lógica do Cálculo".

A metodologia adotada mostra a possibilidade de rompimento desse ensino instituído na educação Matemática, e, mais do que isto, apresenta, por meio de seu potencial teórico e metodológico, a viabilidade de inovação na área da Matemática, ou seja, a oportunidade de se escrever uma nova história na educação, marcada pela ação efetiva do aluno sobre o conhecimento e o prazer em aprender Matemática. A inquietação geradora deste estudo, ora concluído, não se esgota a partir 
eISSN: $2526-9062$

dos resultados alcançados; pelo contrário, abre vasta gama de possibilidades e de sugestões para novos estudos, pois a metodologia "Lógica do Cálculo", provavelmente, seja uma de tantas alternativas de se reestruturar o ensino da Matemática.

\section{Referências}

DANTE, L. R. (1996). Didática da Matemática na pré-escola. São Paulo: Ática.

FAYOL, M. (2012). Numeramento: aquisição das competências Matemáticas. São Paulo: Parábola Editorial.

FONSECA, C. C. da. (2014). O ensino de Matemática e a prática da lógica do cálculo: uma análise da proposta de Ursula Marianne Simons. 150 f. Dissertação (Mestrado em Educação) Centro Universitário La Salle, Canoas, 2014. Disponível em:

<http://biblioteca.unilasalle.edu.br/docs_online/tcc/mestrado/educacao/2014/ccfonseca.pdf > Acesso em: 24 nov. 2018.

FRIEDMANN, A. (1996). Brincar: crescer e aprender - o resgate do jogo infantil. São Paulo: Moderna.

GAUTHIER, C. et al. (2013). Por uma teoria da pedagogia. 3. ed. Ijuí: Editora Unijuí.

GOULART, I. B. (1993). Piaget. Experiências básicas para utilização pelo professor. 8. ed. Petrópolis: Vozes.

LEMOV, D. (2011). Aula nota 10: 49 técnicas para ser um professor campeão de audiência. São Paulo: Boa Prosa.

LÜDKE, M.; ANDRÉ, M. E. D. A. Pesquisa em educação: abordagens qualitativas. São Paulo: EPU, 1986.

MORAES, R.; GALIAZZI, M. do C. (2012). Análise textual discursiva. Ijuí: Editora Unijuí.

PIAGET, J. (2007). Epistemologia genética. 3. ed. São Paulo: Martins Fontes.

PIAGET, J.; INHELDER, B. (1999). A psicologia da criança. Rio de Janeiro: Bertrand Brasil.

SANTOS, L. R.; MATOS, M. L.; SANT’ANA, I. P. (2021). As tendências em educação Matemática na percepção de professores de Matemática. Revista De Educação Matemática, 18, e021005.

SIMONS, U. M.; OLIVEIRA, Ana Maria Nauiack de. (2003). Lógica do cálculo 1. Curitiba: Qualogic. 
eISSN: $2526-9062$

SIMONS, U. M.; OLIVEIRA, Ana Maria Nauiack de. (2009). Metodologia aplicada: lógica do cálculo 1. Curitiba: Qualogic.

SIMONS, U. M. (2013). Metodologia lógica do cálculo. Curso de Formação de Professores. Canoas.

TRIVIÑOS, A. N. S. (2008). Introdução à pesquisa em ciências sociais. A pesquisa qualitativa em educação. São Paulo: Atlas.

VASCONCELLOS, C. dos S. (1994). Disciplina: construção da disciplina consciente e interativa em sala de aula e na escola. São Paulo: Libertad Editora.

YIN, R. K. (2001). Estudo de caso: planejamento e métodos. Porto Alegre: Bookman. 